\title{
Prevalence of liver flukes infections and hydatidosis in slaughtered sheep and goats in Nishapour, Khorasan Razavi, Iran
}

\author{
Majid Aminzare ${ }^{1}$, Mohammad Hashemi², Samaneh Yaghoobi Faz ${ }^{3}$, Mojtaba Raeisi ${ }^{4}$ and Hassan Hassanzadazar ${ }^{1}$
}

1. Department of Food Safety and Hygiene, School of Public Health, Zanjan University of Medical Sciences, Zanjan, Iran

2. Department of Nutrition, Faculty of Medicine, Mashhad University of Medical Sciences, Mashhad, Iran; 3. Department of Food Hygiene and Aquaculture, Faculty of Veterinary Medicine, Ferdowsi University of Mashhad, Mashhad, Iran;

4. Cereal Health Research Center, Golestan University of Medical Sciences, Gorgan, Iran.

Corresponding author: Hassan Hassanzadazar, e-mail: Hassanzadazar_h@zums.ac.ir

Co-authors: MA: m.aminzare@zums.ac.ir, MH: HashemiMD@mums.ac.ir, SYF: Yaghoobi.samane@gmail.com, MR: drmraeisi@goums.ac.ir

Received: 28-08-2017, Accepted: 26-12-2017, Published online: 09-02-2018

doi: 10.14202/vetworld.2018.146-150 How to cite this article: Aminzare M, Hashemi M, Faz SY, Raeisi M, Hassanzadazar H (2018) Prevalence of liver flukes infections and hydatidosis in slaughtered sheep and goats in Nishapour, Khorasan Razavi, Iran, Veterinary World, 11(2): 146-150.

\begin{abstract}
Background: Food-borne trematode infections and hydatidosis are endemic diseases caused by helminths in Iran that are responsible for great economic loss and getting public health at risk.
\end{abstract}

Aim: Aim of this study was to determine the prevalence of fasciolosis, dicrocoeliasis, and hydatidosis infections in slaughtered sheep and goats in Nishapour, Khorasan Razavi province of Iran.

Materials and Methods: A survey was implemented on 130,107 sheep and goats slaughtered at an abattoir in Nishapour (Neyshbur) city, north central Khorasan Razavi Province, Iran, to determine the prevalence of fascioliasis, dicrocoeliosis and presence of hydatidosis.

Results: During a 1-year period of study, among 130,107 of sheep and goats slaughtered at Nishapour abattoir, 1064 and 7124 livers were condemned totally and partially, respectively. A total of $255(0.19 \%), 181(0.12 \%)$, and $7751(5.95 \%)$ of livers were condemned due to cysts of Echinococcus granulosus, flukes of Fasciola spp., and Dicrocoelium dendriticum, respectively. Totally, $1932(1.48 \%)$ lungs were condemned due to hydatidosis. The significant seasonal pattern was seen for fasciolosis, dicrocoeliosis, and hydatidosis, statistically $(\mathrm{p}<0.01)$.

Conclusion: According to this study, it seems that Neyshabour is considered as an endemic region for Fasciola spp. and $D$. dendriticum infections and $D$. dendriticum is the most widespread liver fluke found in sheep and goats.

Keywords: Dicrocoeliasis, Fascioliasis, Hydatidosis, sheep and goat, slaughterhouse.

\section{Introduction}

Fasciola spp., Dicrocoelium dendriticum, and Echinococcus granulosus are the most common helminths that are found in many parts of the world including Iran [1,2]. Liver and lungs are important organs that are usually infected with these parasites. Parasitic infections in ruminants such as food-borne trematode infections and hydatidosis are endemic diseases caused by helminths in Iran that are responsible for great economic loss due to many disorders which results in mortality, reduction of milk production, loss of weight gain, cachexia, condemnation of livers and lungs, high susceptibility to secondary infections and getting public health at risk $[3,4]$.

Fascioliasis (fasciolosis) and dicrocoeliasis are the two endemic parasitic diseases of Iran. Liver fluke infections (Fasciola spp. and D. dendriticum)

Copyright: Aminzare, et al. Open Access. This article is distributed under the terms of the Creative Commons Attribution 4.0 International License (http://creativecommons.org/licenses/ by/4.0/), which permits unrestricted use, distribution, and reproduction in any medium, provided you give appropriate credit to the original author(s) and the source, provide a link to the Creative Commons license, and indicate if changes were made. The Creative Commons Public Domain Dedication waiver (http:// creativecommons.org/publicdomain/zero/1.0/) applies to the data made available in this article, unless otherwise stated. were seen in most of herbivorous mammals such as sheep, goats, cattle, buffaloes, and human as definitive hosts for these parasites. Sheep are particularly susceptible to hepatic trematodes including Fasciola hepatica, Fasciola gigantica, and D. dendriticum. They are the most important trematodes of domestic ruminants and a common cause of liver fluke disease particularly $F$. hepatica in temperate areas of the world, Middle East including Iran [1,5-9]. Presence of freshwater snail species of the family Lymnaeidae (Limnea species) as intermediate host is the distribution agent of the fascioliasis disease in each area $[3,10]$. Several studies demonstrated the presence of fasciolosis in many provinces of Iran including Arak, Khuzestan, Mazandaran, Kurdistan, Kermanshah, Tehran, Zanjan, Azerbaijan, Gilan, and Fars $[1,3,4,11,12]$. Studies showed that prevalence of fasciolosis among domestic animals is higher in the southern part of Iran, but the incidence of the human disease is significantly higher in the Northern provinces [1]. Symptoms of dicrocoeliasis in domestic animals is less severe than fasciolosis, but its economic losses mainly as a result of affected liver condemnation are notable $[1,13]$. In a cross-sectional study during 5 years (2003-2007), Tavakoli et al. [14] 
reported that among studied provinces the highest fasciolosis and dicrocoeliasis infections rate were in Gilan (20.91\%), Mazandaran (16.36\%), and Esfahan $(9.95 \%)$ provinces, respectively, while the lowest infection rate was seen in Ilam $(0.76 \%)$, Boushehr $(0.84 \%)$, and Yazd $(1.51 \%)$, respectively.

Cystic echincoccosis (CE) or hydatid cyst known as hydatidosis is the larval form of E. granulosus in intermediate hosts that can also cause considerable economic losses and public health problems [15]. Studies have shown a high incidence of CE in animals in developing countries, Mediterranean, Middle East and south west of Asia including Iran in sheep, goats, cattle, buffaloes, and camels [15-19].

Due to great medical and veterinary importance of fasciolosis, dicrocoeliasis, and hydatidosis around the world including in Iran and the scarcity of information on the prevalence of these three parasitical infections in slaughtered animals in Nishapour abbatoir, Iran; therefore, the purpose of this study was to determine the prevalence of fasciolosis, dicrocoeliasis, and hydatidosis infections in slaughtered sheep and goats in Shahroud, Semnan province of Iran.

\section{Materials and Methods}

\section{Ethical approval}

animals.

Samples were collected from slaughtered

\section{Study area and samples}

In this cross-sectional survey, the total numbers of slaughtered sheep and goats, liver condemnations due to these three parasitical infections and both liver and lung condemnations due to hydatid cysts were recorded during March 2016-March 2017 at an abattoir in Nishapour (Neyshbur) city, north central Khorasan Razavi Province, Iran, with long periods in the range of $58^{\circ}$ and $8 \mathrm{~min}$ to $59^{\circ}$ and $20 \mathrm{~min}$ of longitude and $35^{\circ}$ and $35 \mathrm{~min}$ to $36^{\circ}$ north latitude and $52 \mathrm{~min}$, in fact. Nishapour as the second largest city of Khorasan Razavi province situated in a fertile plain at the foot of the Binalud Mountains has a generally Mediterranean climate with the rainy seasons mostly in the spring and winter.

\section{Parasitological examination}

Liver and lungs of 130,107 sheep and goats were inspected according to the method described by Ogambo-Ongoma [20] to recognize fasciolosis and dicrocoeliosis and for the presence of cysts of echinococcosis. The parasites were identified by their morphological characteristics $[4,15]$. Visualization, palpation, and incision of livers and lungs were used to extract the prevalence of these parasites. The prevalence was reported seasonally to determine the difference between distributions of infections.

\section{Statistical analysis}

SPSS software Version 16 (SPSS Inc., Chicago, IL, USA) was used for analyzing data. One way ANOVA and chi-square tests were used to determine contamination abundance and seasonal prevalence correlation, respectively.

\section{Results}

During 1-year period of study, among 130,107 of sheep and goats slaughtered at Nishapour abattoir, 1064 and 7124 livers were condemned totally and partially, respectively (Table- 1$)$. A total of $255(0.19 \%)$, $181(0.12 \%)$, and $7751(5.95 \%)$ of livers were condemned due to cysts of E. granulosus, flukes of Fasciola spp., and $D$. dendriticum, respectively. Totally 1932 (1.48\%) of lungs were condemned due to hydatid cysts significant seasonal pattern was seen for fasciolosis, dicrocoeliosis, and hydatidosis, statistically $(\mathrm{p}<0.01)$ (Figure-1).

\section{Discussion}

According to obtained results, the prevalence of fasciolosis, dicrocoeliosis, and hydatidosis was high in Nishapour (Neyshbur) city. Parasites are different in the complexity of their lifecycles. Some of them complete their lifecycle in a single host (simple lifecycle parasites), while others complete it in multiple hosts (complex lifecycle parasites [CLPs]) [21]. Fasciolosis, dicrocoeliosis, and hydatidosis are CLPs, so all factors that impact on the final or intermediate host presence can increase their prevalence. Mediterranean climate with the rainy seasons mostly in the spring and winter, the presence of green pastures and the large number and variety of livestock in this region are the main reasons for high prevalence [22]. Many reports are present of the high occurrence of these zoonotic infections in many Iranian provinces, particularly in north, northwest, and northeast provinces [14,21]. The infection rate is lower in center and southern provinces of Iran due to the low population of livestock, lack of intermediate hosts of parasites and environmental harshness [14,21]. In Iran, the average prevalence of $17.8 \%, 19 \%, 11.5 \%$, and $34.6 \%$ fasciolosis has been reported in cattle, sheep, goats, and camels, respectively $[10,18]$. In the present study in comparison, the lower average prevalence of $(0.12 \%)$ fasciolosis in slaughtered sheep and goats and liver condemnation due to low infestation was recorded. The prevalence of liver fasciolosis was reported variously throughout the world and Iran. Infection rate of fasciolosis in Pakistan, Turkey, Nigeria, and Saudi Arabia was reported $51.3 \%$ and $14.8 \%, 3.99 \%, 9-10.3 \%, 0.04 \%$, and $0.00 \%$ in sheep and goats, respectively [23-26]. Khanjari et al. [1], Sayadi et al. [11], Ansari-Lari and Moazzeni [3], and Ezatpour et al. [27] reported prevalence of fasciolosis in sheep $6.6 \%, 1.12 \%, 2.9 \%$, and $6.3 \%$ in Mazandaran (Amol), Arak, Shiraz and Lorestan provinces, respectively. Goats infestation was lower than in sheep due to grazing on leaves and branches on trees and bushes whereas sheep graze on plants on the ground $[3,11,28]$. Availability of suitable habitat for snails as intermediate hosts, temperature and humidity are the main factors to consider in the epidemiology of fasciolosis [10]. 
Table-1: Contamination abundance of fasciolosis, dicrocoeliosis, and hydatidosis in the slaughterhouse of Nishapour during March 2016-March 2017.

\begin{tabular}{|c|c|c|c|c|c|c|}
\hline \multirow[t]{2}{*}{ Season } & \multirow[t]{2}{*}{ Slaughtered } & \multicolumn{2}{|c|}{ Fasciolosis (liver) } & \multirow{2}{*}{$\begin{array}{c}\begin{array}{c}\text { Dicrocoeliosis (liver) } \\
\text { condemnation }\end{array} \\
\text { Totally condemned }(\%)\end{array}$} & \multicolumn{2}{|c|}{$\begin{array}{c}\text { Hydatidosis } \\
\text { (liver and lung) } \\
\text { condemnation }\end{array}$} \\
\hline & & $\begin{array}{c}\text { Totally } \\
\text { condemned (\%) }\end{array}$ & $\begin{array}{c}\text { Partially } \\
\text { condemned (\%) }\end{array}$ & & Liver (\%) & Lung (\%) \\
\hline Spring & 27188 & $14(0.05)$ & $21(0.08)$ & $1048(3.85)$ & $54(0.2)$ & $438(1.61)$ \\
\hline Summer & 40030 & $22(0.05)$ & $0(0)$ & $1852(4.63)$ & $102(0.25)$ & $494(1.23)$ \\
\hline Autumn & 31806 & $13(0.04)$ & $17(0.05)$ & $2082(6.55)$ & $51(0.16)$ & $598(1.88)$ \\
\hline Winter & 31083 & $94(0.3)$ & $0(0)$ & $2769(8.91)$ & $48(0.15)$ & $402(1.29)$ \\
\hline Total & 130107 & $143(0.11)$ & $38(0.03)$ & $7751(5.96)$ & $255(0.2)$ & $1932(1.48)$ \\
\hline
\end{tabular}

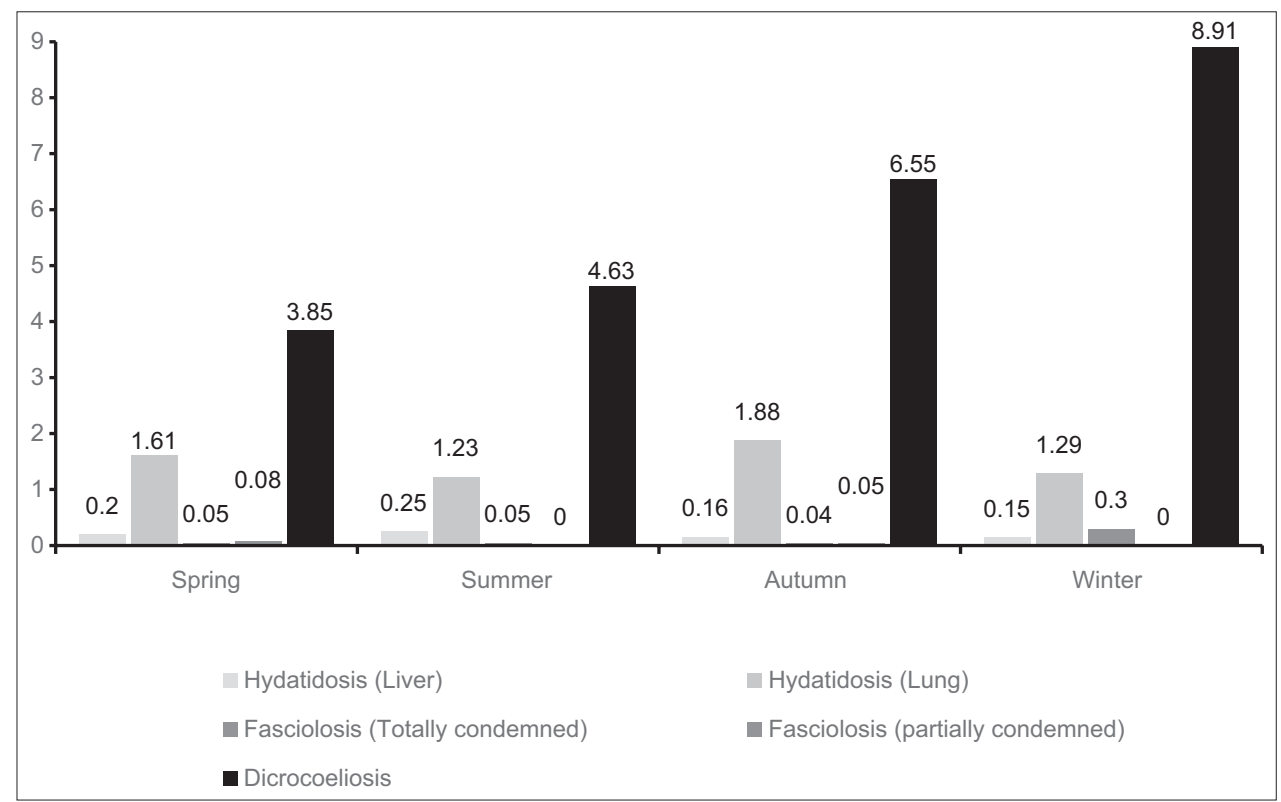

Figure-1: Seasonal pattern of prevalence (\%) of hydatidosis (liver), hydatidosis (lung), Fasciolosis, and Dicrocoeliosis in slaughtered animals at Neyshabour abattoir during March 2016-March 2017.

Dicrocoeliasis was responsible for 5.95\% of liver condemnations in this study. Prevalence of dicrocoeliosis was higher than fasciolosis $(0.12 \%)$ in this study, in both sheep and goat that slaughtered in Neyshabour abattoir. These results are consistent with reports of Oryan et al. [29], Khanjari et al. [30], Mirzaei et al. [4], Movassagh and Valilou [31], Gargili et al. [24], and Ansari-Lari and Moazzeni [3], but were inconsistent with the data reported by Sayadi et al. [11], and Radfar and Sakha [32]. The high occurrence of dicrocoeliasis can be related to various factors such as soil type (calcareous or alkaline soils), local environmental, ecological factors, and low requirements of intermediate hosts of Dicrocoelium to moisture [3,29]. Sheep are more susceptible than goats to $D$. dendriticum $[1,33]$.

Another prevalent disease in livestock of many Iranian provinces is hydatid cysts, in particular in regions with green pastures and a high number of livestock such as North, northeast, and west provinces $[14,22,34]$. The occurrence of hydatidosis in sheep and goats was found to be $1.67 \%$ during the study period which is lower than average prevalence of hydatidosis in animals in Iran $(8.1 \%)[3,22]$. The lowest prevalence of hydatidosis was reported in goats, probably due to the diet of goats [15]. In the present study, the prevalence of hydatidosis was higher in lungs $(1.48 \%)$ than in livers $(0.19 \%)$. Several studies were implemented to determine the prevalence of hydatidosis in livers and lungs of livestock throughout the world and Iran. Azami et al. [15], Kebede et al. [35], Mohamadzadeh et al. [36], Yaghan et al. [37], Abdi et al. [38], and Faraji et al. [39] were reported liver infection of sheep $16.4 \%, 0.86$ $\%, 2.25 \%, 10.6 \%$, and $4 \%$, respectively. A comparison between the results of the present study with the above studies reveals that the infection of hydatidosis in Neyshabour is different probably due to a different distribution pattern of the parasite. Variation in prevalence depends on several factors including strain differences of $E$. granulosus in different geographical locations, age of animal, different in culture, social activities, lack of standardized of animal health services, vicinity of animals with dogs and presence of wild carnivores such as foxes, wolves, jackals, and Hyenas [15,36,40,41].

Seasonal pattern of prevalence (\%) and statistical analysis (Chi-square test) was shown a significant correlation between fasciolosis, dicrocoeliosis, and 
Table-2: Fasciolosis, dicrocoeliosis, and hydatidosis prevalence (\%) and seasonal correlation (Chi-square test).

\begin{tabular}{lcccrr}
\hline Parasitic infection & Spring & Summer & Autumn & Winter & p value \\
\hline Hydatidosis (liver) & 0.20 & 0.25 & 0.16 & 0.15 & 0.0077 \\
Hydatidosis (lung) & 1.61 & 1.23 & 1.88 & 1.29 & $<0.001$ \\
Fasciolosis (totally condemned) & 0.05 & 0.05 & 0.04 & 0.3 & $<0.001$ \\
Fasciolosis (partially condemned) & 0.08 & 0 & 0.05 & 0 & $<0.001$ \\
Dicrocoeliosis & 3.85 & 4.63 & 6.55 & 8.91 & $<0.001$ \\
\hline
\end{tabular}

hydatidosis prevalence and seasons in this study $(p<0.01)$ (Figure-1 and Table-2). In all animal species (sheep and goats, respectively) in this study, the highest infection rate due to Fasciola spp. and D. dendriticum was seen in the winter and the autumn and winter, respectively (Figure-1). The highest seasonal prevalence of hydatidosis especially lung form was seen in autumn and winter seasons (Figure-1). Fluke eggs hatching and their surviving ability, environmental condition, intermediate hosts multiplying and animals movement from lowland to mountain pastures where they become infected by the intermediate hosts (such as ants for dicrocoeliosis) and then bring the infection back to the valley during the winter are the main reasons of high prevalence in certain seasons $[1,27,42]$. Moreover, high stress induced by the transhumance on pasture-grazing nomadic sheep and goats during migratory period seems to predispose animals to infection [27,29,33].

\section{Conclusion}

According to this study, it can be concluded that Neyshabour is considered as an endemic region for Fasciola spp. and D. dandriticum infection. $D$. dandriticum is the most widespread liver fluke found in sheep and goats. It seems that direct inspection method still is the best approach to estimate the prevalence of liver flukes and hydatidosis in livestock. More actions are suggested to formulate appropriate control strategies to decrease diseases and economic loss due to the condemnation of infected livers in Iran. Some treatment strategies with anthelminthic drugs and education of ranchers, safe disposal of infected offal in slaughterhouses, treatment of stray dogs as E. granulosus spreader are recommended. Parallel with the application of control measures; further surveys are strongly recommended collect more data about the liver flukes infection prevalence and risk factors for developing a prediction model in small ruminants in the study area and Iran.

\section{Authors' Contributions}

MA and MH planned and designed for the study. The Data were collected in the fields by SYF and MR. MA and HH analyzed the data and achieved statistical analysis. HH drafted and revised the manuscript. Finally, all authors read and approved the final manuscript.

\section{Acknowledgments}

Authors thank education deputy of Zanjan University of Medical Sciences for financial support (Grant No. A-10-47-1) and the authorities of Neyshabur slaughterhouses (Iran) for assistance in collecting samples.

\section{Competing Interests} interests.

The authors declare that they have no competing

\section{References}

1. Khanjari, A., Bahonar, A., Fallah, S., Bagheri, M., Alizadeh, A., Fallah, M. and Khanjari, Z. (2014) Prevalence of fasciolosis and dicrocoeliosis in slaughtered sheep and goats in Amol Abattoir, Mazandaran, northern Iran. Asian Pac. J. Trop. Dis., 4(2): 120-124.

2. Kantzoura, V., Kouam, M.K., Feidas, H., Teofanova, D. and Theodoropoulos, G. (2011) Geographic distribution modelling for ruminant liver flukes (Fasciola hepatica) in south-eastern Europe. Int. J. Parasitol., 41(7): 747-753.

3. Ansari-Lari, M. and Moazzeni, M. (2006) A retrospective survey of liver fluke disease in livestock based on abattoir data in Shiraz, South of Iran. Prev. Vet. Med., 73: 93-96.

4. Mirzaei, M., Rezaei, H. and Nematollahi, A. (2015) Role of ruminants in the epidemiology of Echinococcus granulosus in Tabriz area, Northwest of Iran. Trop. Biomed., 32(2): 269-275.

5. Mungube, E.O., Bauni, S.M., Tenhagen, B.A., Wamae, L.W., Nginyi, J.M. and Mugambi, J.M. (2006) The prevalence and economic significance of Fasciola gigantica and stilesia hepatica in slaughtered animals in the semi-arid coastal Kenya. Trop. Anim. Health Prod., 38: 475-483.

6. Sissay, M.M., Uggla, A. and Waller, P.J. (2007) Prevalence and seasonal incidence of nematode parasites and fluke infections of sheep and goats in eastern Ethiopia. Trop. Anim. Health Prod., 39(7): 521-531.

7. Liba, J.W., Atsanda, N.N. and Francis, M.I. (2017) Economic loss from liver condemnation due to fasciolosis in slaughtered ruminants in Maiduguri abattoir, Borno State, Nigeria. J. Adv. Vet. Anim. Res., 4(1): 65-70.

8. Khoramian, H., Arbabi, M., Mahami, O.M., Delavari, M., Hooshyar, H. and Asgari, M. (2014) Prevalence of ruminants fascioliasis and their economic effects in Kashan, center of Iran. Asian Pac. J. Trop. Biomed., 4(11): 918-922.

9. Jemal, D. and Kebede1, B. (2016) The study of major parasitic causes of organ condemnation and financial losses in cattle slaughtered at Hawassa municipal Abattoir, Ethiopia. Cogent. Food Agric., 2: 1201183.

10. Khosravi, A. and Babaahmady, E. (2012) Epidemiology of Fasciola hepatica in Iran. Int. J. Biol., 4(4): 86-90.

11. Sayadi, M., Rezaei, M., Jahanbakhsh, M.I., Gholamrezaei, M., Mohammadpourfard, I., Yahyaei, M. and Esmaeili, R. (2015) The prevalence of fascioliasis in slaughtered animals of the Industrial Slaughterhouse of Arak, Iran (2007-2010). Iran. J. Health Sci., 3(4): 59-64.

12. Ahmadi, N.A. and Meshkehkar, M. (2010) Prevalence and long term trend of liver fluke infections in sheep, goats and cattle slaughtered in Khuzestan, southwestern Iran. $J$. Paramed. Sci., 1(2): 26-31.

13. Ahmadi, R., Sikejor, E.M. and Maleki, M. (2010) Prevalence of $D$. dendriticum infection in cattle, sheep and goat in Gilan province, Northern Iran. J. Anim. Vet. Adv., 
9(21): 2723-2724

14. Tavakoli, H.R., Mahmoodzadeh, A. and Hajia, M. (2008) A five years study of fascioliasis and Dicrocoeliasis in Iran's slaughterhouses. Asian Pac. J. Trop. Med., 1(4): 9-13.

15. Azami, M., Anvarinejad, M., Ezatpour, B. and Alirezaei, M. (2013) Prevalence of hydatidosis in slaughtered animals in Iran. Turk. J. Parasitol., 37: 102-106.

16. Qingling, M., Guanglei, W., Jun, Q., Xinquan, Z.H., Tianli, L., Xuemei, S., Jinsheng, ZH., Huisheng, W. Kuojun, C. and Chuangfu, C.H. (2014) Prevalence of hydatid cysts in livestock animals in Xinjiang, China. Korean J. Parasitol., 52(3): 331-334.

17. Yibar, A., Selcuk, O. and Senlik, B. (2015) Major causes of organ/carcass condemnation and financial loss estimation in animals slaughtered at two abattoirs in Bursa Province, Turkey. Prev. Vet. Med., 118(1): 28-35.

18. Dalimi, A., Motamedi, G., Hosseini, M., Mohammadian, B., Malaki, H., Ghamari, Z. and Ghaffari, F.F. (2002) Echinococcosis/hydatidosis in western Iran. Vet. Parasitol., 105: 161-171.

19. Miran, M.B., Kasuku, A.A. and Swai, E.S. (2017) Prevalence of echinococcosis and Taenia hydatigena cysticercosis in slaughtered small ruminants at the livestock-wildlife interface areas of Ngorongoro, Tanzania. Vet. World, 10(4): 411-417.

20. Ogambo-Ongoma, A.H. (1972) Fascioliasis survey in Uganda. Bull. Epizoot. Dis. Afr., 20: 35-41.

21. Auld, S.K.J.R. and Tinsley, M.C. (2015) The evolutionary ecology of complex lifecycle parasites: Linking phenomena with mechanisms. Heredity (Edinb), 14(2): 125-132.

22. Mansoorlakooraj, H., Saadati, D., Javadi, R., Heydari, S., Torki, E. and Gholami, H. (2011) A survey on hydatidosis in livestock in Northern Iran based on data collected from slaughterhouses from 2004 to 2008. Vet. Parasitol., 182: $364-367$

23. Sharma, R. and Raina, O. (1989) Studies on the prevalence and laboratory transmission of fascioliasis in animals in the Kashmir valley. Brit. Vet. J., 145: 57-61.

24. Gargili, A., Tuezer, E., Guelanber, A., Toparlak, M., Efil, I., Keles, V. and Ulutas, M. (1999) Prevalence of liver fluke infections in slaughtered animals in Trakya (Thrace), Turkey. Turk. J. Vet. Anim. Sci., 23: 115-116.

25. Liba, J.W., Francis, M.I. and Atsanda, N.N. (2017) Seasonal prevalence and comparison between sensitvity of conventional and serological detection of fasciolosis in ruminants slaughtered in Maiduguri abattoir, northeast Nigeria. Bull. Anim. Hlth. Prod. Afr., 65: 25-35.

26. Theodoropoulos, G. (2011) Risk factors and geospatial modelling for the presence of Fasciola hepatica infection in sheep and goat farms in the Greek temperate Mediterranean environment. J. Parasitol., 138: 926-938.

27. Ezatpour, B., Hasanvand, A., Azami, M., Anbari, K.H. and Ahmadpour, F. (2015) Prevalence of liver fluke infections in slaughtered animals in Lorestan, Iran. J. Parasit. Dis.,
39(4): 725-729.

28. Mohammadpourfard, I., Rezaei, M., Sayadia, M., Shariatifar, N., Behzadi, A.A. and Karimi, F. (2015) Prevalence of dicrocoeliosis in slaughtered herbivores animals in Arak city of Markazi province in Iran. J. Food Saf. Hyg., 1(1): 18-21.

29. Oryan, A., Mansourian, M., Moazeni, M., Nikahva, L.B. and Barband, S. (2011) Liver distomatosis in cattle, sheep and goats of Northeastern Iran. Glob. Vet., 6(3): 241-246.

30. Khanjari, A., Partovi, R., Abbaszadeh, S., Nemati, G., Bahonar, A., Misaghi. A. and Akhondzadeh-Basti, A. (2010) A retrospective survey of fasciolosis and dicrocoeliosis in slaughtered animals in Meisam Abattoir, Tehran, Iran (2005-2008). Vet. Res. Forum., 1: 174-178.

31. Movassagh, G.M. and Valilou, M. (2008) The prevalence of sheep liver trematodes in the Northwest Region of Iran. Turk. J. Vet. Anim. Sci., 32(4): 305-307.

32. Radfar, M. and Sakha, M. (2000) Prevalence of liver trematodes in sheep slaughtered in Kerman, in proceedings. NICOPA $3^{\text {rd }}$, Sari, Iran., p. 286-287.

33. Otranto, D. and Traversa, D. (2003) Dicrocoeliosis of ruminants: A little known fluke disease. Trends Parasitol., 19(1): 12-15.

34. Movassagh, G.M., Valilou, M.R., Kharati, F.B. and Zirak, K. (2008) Prevalence of sheep liver hydatid cyst in the northwest region of Iran. Asian J. Anim. Vet. Adv., 3: 30-35.

35. Kebede, N., Mitiku, A. and Tilahun, G. (2009) Hydatidosis of slaughtered animals in Bahir Dar Abattoir, Northwestern Ethiopia. Trop. Anim. Health Prod., 41(1): 43-50.

36. Mohamadzadeh, T., Shams, S., Khanaliha, K., Marhamatizadeh, M.H. and Vafa, A. (2016) A study on prevalence of some helminthic infections of the liver and lungs among ruminants in abattoir of Fars province, Iran. Arch. Razi. Inst., 71(4): 245-251.

37. Yaghan, R.J., Bani-Hani, K.E. and Heis, H.A. (2004) The clinical and epidemiological features of hydatid disease in Northern Jordan. Saudi Med. J., 25: 886-889.

38. Abdi, J., Taherikalani, M., Asadolahi, K.H. and Emaneini, M. (2013) Echinococcosis/Hydatidosis in Ilam province, Western Iran. Iran. J. Parasitol., 8(3): 417-422.

39. Faraji, R., Javadi, G.H., Mohamadi, B.P., Ahmadian, F., Sarebanhassanabadi, M., Dehghani, F.A. and Moloudi, A. (2015) Prevalence of hydatid cyst in slaughtered livestock in Kermanshah (West Iran). Adv. Microbiol., 5: 252-257.

40. Roostaei, M., Fallah, M., Maghsood, A.H., Saidijam, M. and Matini, M. (2017) Prevalence and fertility survey of hydatid cyst in slaughtered livestock in Hamadan Abattoir, Western Iran, 2015-2016. Avicenna J. Clin. Microb. Infec., 4(2): e43361.

41. Arbabi, M. and Hooshyar, H. (2006) Survey of echinococcosis and hydatidosis in Kashan Region, Central Iran. Iran. J. Publ. Health, 35(1): 75-81.

42. Taylor, M. (2012) Emerging parasitic diseases of sheep. Vet. Parasitol., 189(1): 2-7. 